\title{
Common Tag STSs in the AZF Region Associated with Azoospermia and Severe Oligospermia in Infertile Egyptian Men
}

\author{
Nasser A. Elhawary ${ }^{1,2, *}$, Neveen S. Seif-Eldin ${ }^{3}$, Marwa Zaki $^{3}$, Heba Diab $^{3}$, Salwa Teama ${ }^{4}$ and \\ Saleh A. Saleh ${ }^{5,6}$ \\ ${ }^{I}$ Department of Medical Genetics, Faculty of Medicine, Umm Al-Qura University, Makkah, KSA \\ ${ }^{2}$ Department of Molecular Genetics, Medical Genetics Center, Faculty of Medicine, Ain Shams University, Cairo, Egypt \\ ${ }^{3}$ Department of Dermatology, Venereology \& Andrology, Faculty of Medicine, Ain Shams University, Cairo, Egypt \\ ${ }^{4}$ Department of Clinical Pathology, Medical Research Center, Ain Shams University Cairo, Egypt \\ ${ }^{5}$ Department of Biochemistry, Faculty of Medicine, Umm Al-Qura University, Makkah, KSA \\ ${ }^{6}$ Oncology Diagnostic Unit, Faculty of Medicine, Ain Shams University, Cairo, Egypt
}

\begin{abstract}
Screening of $Y q$ has become one of the most frequently performed postnatal molecular genetic tests in Egypt. Our purpose was to determine the tag sequence-tagged sites (STSs) in the AZF -region of $Y q$ associated with azoospermia and severe oligospermia in infertile Egyptian men. We analyzed blood samples from 49 infertile men (28 with azoospermia and 21 with severe oligospermia) using multiplex PCR for six common AZFa, AZFb, and AZFc STS markers, as recommended by the European Academy of Andrology. Twenty-four (37\%) microdeletions with five separate deletions were identified. We found $66.7 \%$ of the deletions in the AZFb locus, $20.8 \%$ in the AZFa locus, and $12.5 \%$ in the AZFc locus. Some common haplotypes (7 of 10) were identified in our sample population. Haplotypes H3 (corresponding to sY127) and $\mathrm{H} 4$ (corresponding to sY134) were the most common. We suggest that screening with a minimum of three STSs-sY86, sY127, and sY134-would provide the highest level of clinical sensitivity in genetic testing among infertile Egyptian men. Moreover, separate microdeletions were localized in infertile Y-chromosome patients.
\end{abstract}

Keywords: AZF region, Azoospermia, Male infertility, Microdeletions, Oligospermia, Y Chromosome.

\section{INTRODUCTION}

The 10-Mb AZF region on the $\mathrm{q}$ arm of the $\mathrm{Y}$ chromosome is frequently deleted in men with unexplained spermatogenic failure. Microdeletions are linked to AZF loci in $20-30 \%$ of patients with non-obstructive azoospermia and in 3-7\% of patients with severe idiopathic oligospermia [1]. AZF microdeletions are associated with varied testicular histology, ranging from Sertoli-cell-only (SCO) syndrome to hypospermatogenesis to maturation arrest [2]. Although documentation of the prevalence of infertility is lacking in some countries, the Egyptian IVF Center estimates the prevalence to be about $15 \%$. A survey sponsored by the World Health Organization estimated the prevalence of infertility among married Egyptian couples to be $12 \%(4.3 \%$ for primary infertility and $7.7 \%$ for secondary infertility) [3]. In addition, Boivin et al. [4] stated that the prevalence of infertility ranged from $3.5 \%$ to $16.7 \%$ in more developed nations and from $6.9 \%$ to $9.3 \%$ in less-developed nations, with an estimated overall median prevalence of $9 \%$.

The sequence-tagged site (STS) markers of the AZF region have been useful for identifying microdeletions in

*Address correspondence to this author at the Department of Medical Genetics, Faculty of Medicine, P.O. 7607, Umm Al-Qura University, Makkah, KSA; Mobile: +966-553692180; Fax: +966-2-5270000 (ext 4659); E-mail: nasgenet@hotmail.com; naelhawary@uqu.edu.sa
DNA from blood [5] and sperm [6] of infertile men. Most studies have focused on men with low sperm counts, so most of the deletions that have been found are associated with azoospermia and severe oligospermia. The European Academy of Andrology and the European Genetics Quality Network recommend using six STSs to screen the AZF region [7].

Egypt has been the interest of many conquerors since the time of the ancient Pharaohs, including during the Osmani Empire, the French campaign, British domination, and the Arab-Israeli conflict. As a consequence, much social intermarriage between populations [8] admixed the Y chromosomes. In this study, we identified common tag STS markers in azoospermia and severe oligospermia to screen them for $\mathrm{Y}$ chromosome microdeletions before couples initiated assisted reproduction. We extended our work to analyze the testicular phenotypes and the frequency of $Y q$ microdeletions in infertile Egyptian men.

\section{MATERIALS AND METHODOLOGY}

\section{Patients}

Forty-nine infertile men with oligozoospermia or nonobstructive azoospermia (age, 22-45 y; median, 33 y) who were seeking andrologic investigation for male-factor infertility at the Andrology Clinic-Faculty of Medicine, Ain Shams University-Cairo, were included in our study. Non- 
obstructive azoospermia was considered as a result of spermatogenic defects on testicular biopsy or an elevated serum FSH level, total testicular volume $<30 \mathrm{ml}$, and no other applicable diagnosis [9]. These men had a history of at least one year of infertility. Only patients with a normal 46,XY karyotype, as shown by conventional GTG-banding, were included in this study. Moreover, a man was excluded from the study if any problems were found in the female partner. All participants signed a consent form before the study began. Patients were informed about the purpose of the study, blood samples were taken on a single occasion, and all the steps of the tests were explained to the patient along with their possible complications.

\section{Molecular Analysis}

Genomic DNA was isolated from peripheral blood using the QIAamp DNA Blood kit (Qiagen, Hilden, Germany) or from buccal cells [8]. DNA was then analyzed using multiplex PCR to amplify six STSs from the AZF region. Primers covering only regions considered to be hotspots for microdeletions were chosen [10]. These primers corresponded to AZFa (sY84, sY86), AZFb (sY127, sY134), and AZFc (sY254, sY255) (Table 1). We created modified primer mixes for sY84, sY134, and sY255 ( $\operatorname{mix} I$ ), and sY254, sY86, and sY127 (mix II) using sY14 ( $Y p$, internal positive control).

Genomic DNA (250 ng), $5.5 \mu M$ of multiple primer mix (Metabion, GmbH, Germany), and 5\% DMSO were added to Ready-Taq DNA enzyme mix (Fermentas, GmbH, Germany).
We performed 45 rounds of PCR with annealing at $54^{\circ} \mathrm{C}$ and elongation at $65^{\circ} \mathrm{C}$ for $45 \mathrm{~s}$ each. The PCR products were separated on a 3\% MetaPhor gel (BMA, Rockland, ME) stained with ethidium bromide (Fig. 1). All deletions were confirmed by conventional Southern blotting [11].

\section{Haplotype Analysis}

We defined a haplotype as a specific pattern of deletions within a group of STS markers. Based on prior understanding of this region of the $\mathrm{Y}$ chromosome, a minimum number of certain STS markers can be used as tags for specific haplotypes. Using this concept, we estimated haplotype frequencies in our samples, as previously described [12].

\section{Clinical Analyses}

A detailed medical and surgical history, including history of orchitis, mumps, testicular maldescent, testicular injuries, chemotherapy, radiotherapy, smoking, and alcohol habits was taken for each participant. The size, volume, and consistency of the testes, hydrocele, and varicocele were determined, and secondary sexual characteristics were examined. Ultrasonography of the testes was also performed to detect subclinical varicocele and parenchymal lesions compatible with neoplasms.

The diagnosis of azoospermia was established by analyzing the pellet after semen centrifugation [13]. Levels of $\mathrm{LH}, \mathrm{FSH}$, and testosterone were measured using a commercial RIA kit (Pharmacia, GmbH, Germany). Testicular biopsy and histological analysis of spermatogenesis

Table 1. Sizes, Positions, and Primer Sequences of Sequence-Tagged Site (STS) Markers on the Y Chromosome

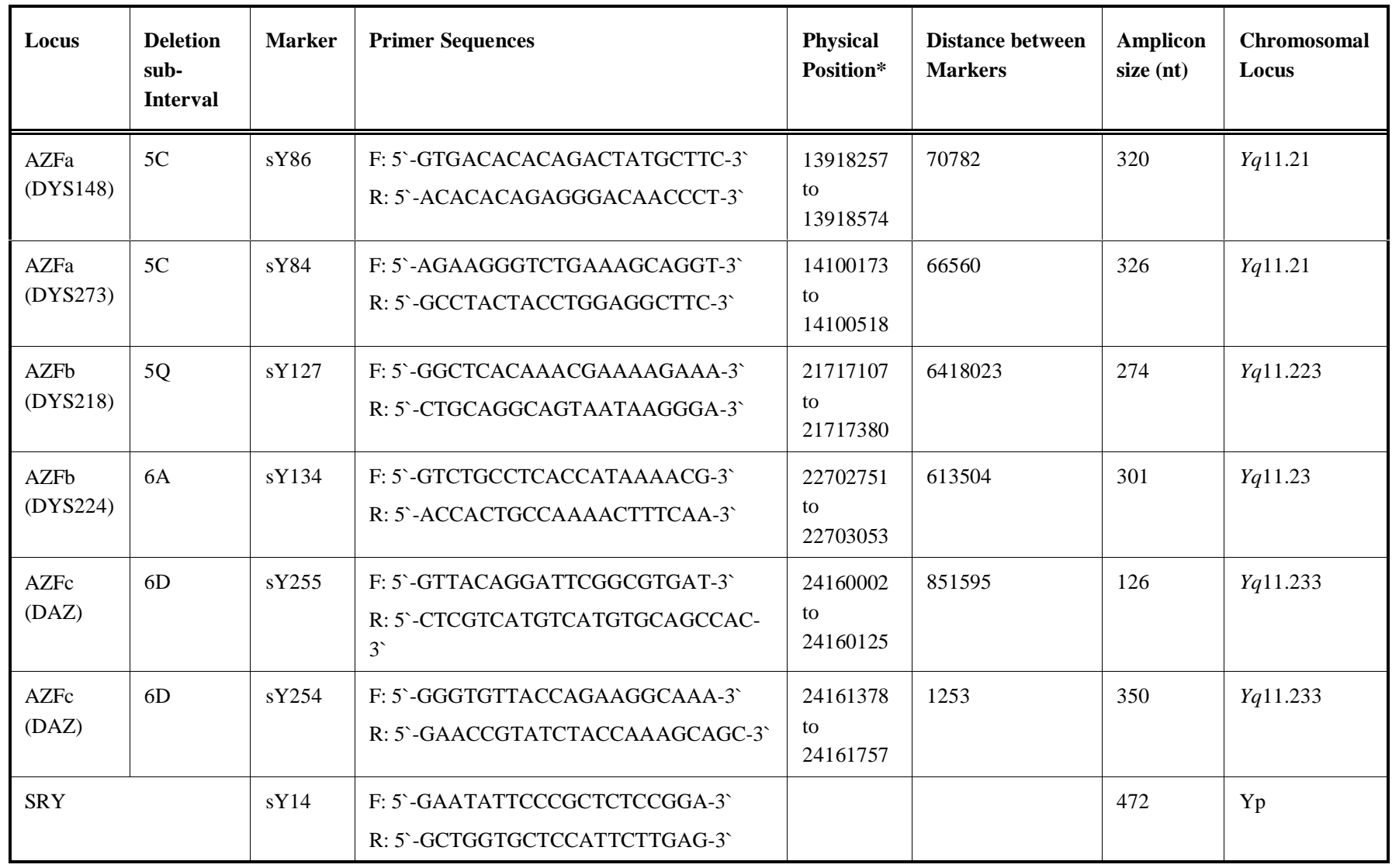

* As reported in release July 2003 of the UCSC (http://genome.ucsc.edu/). 


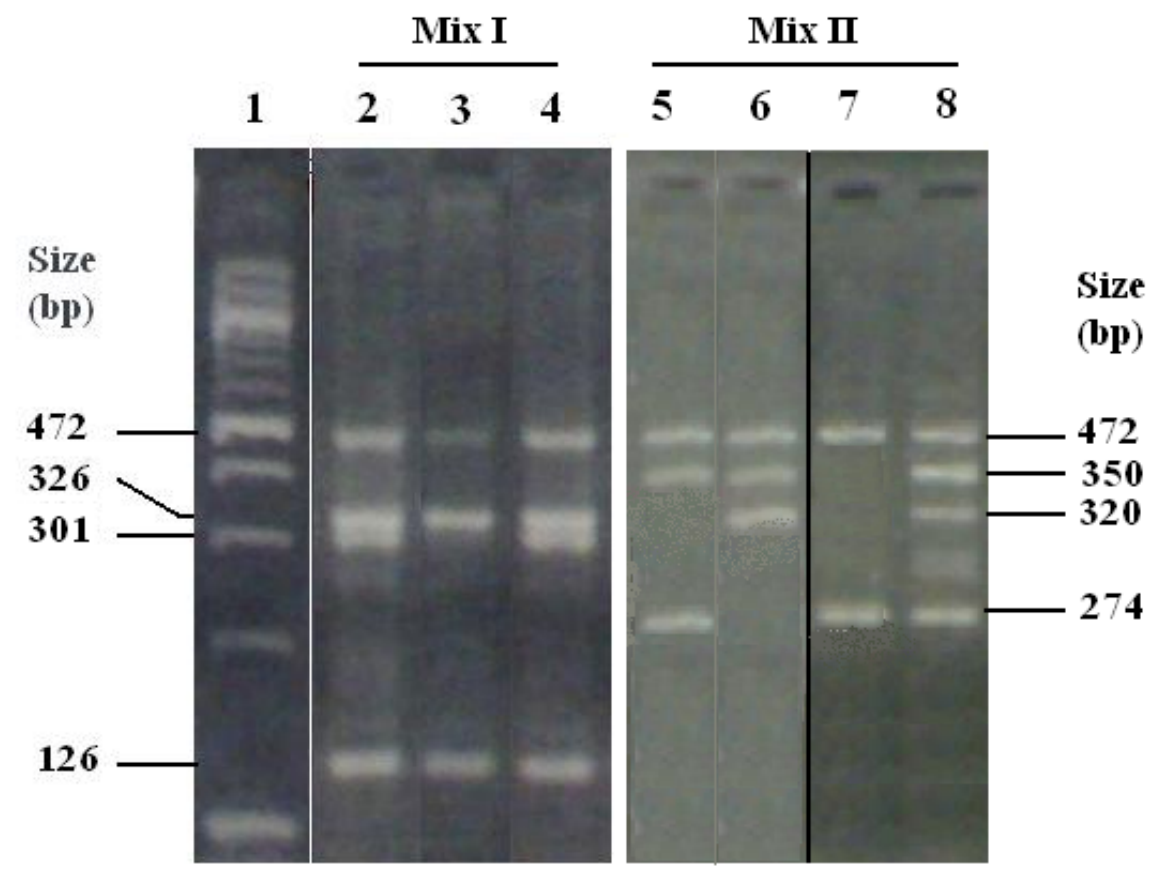

Fig. (1). PCR analysis on DNA of infertile men using sY84, sY134, sY255 (mix I), and sY86, sY127, sY254 (mix II). The fragment due to sY14 'SRY' (472-bp) was used as the internal control. Lane 1, molecular weight (100-bp DNA ladder marker); lanes 2 and 8, normal men with no deletions; lane 3, deletion of sY134; lane 4, infertile man with no deletions. Lanes 5 and 6 , patients with deletions of sY86 and sY127, respectively; lane 7, a patient with large deletions of sY86+sY254.

was performed on haematoxylin- and eosin-stained sections. Four sections were examined per patient. The diameter of the seminiferous tube of each section was measured using an ocular micrometer. The involvement of Sertoli cells in different spermatogenesis impairment was also studied by immunohistomorphometric technique using vimentin as a marker of immature Sertoli cells (Fig. 2). Graphical analyses were performed using Microsoft Excel and SPSS Statistics 17.0 .

\section{RESULTS}

\section{Prevalence of Yq Microdeletions}

To determine the tag STSs associated with azoospermia and severe oligospermia in our population of 49 infertile Egyptian men, we amplified six common STSs on the AZF loci using two multiplex PCRs. We detected $18(37 \%)$ microdeletions in 49 samples. Eleven (39\%) of the samples were from men with azoospermia and 7 (33\%) from men with severe oligospermia. AZFb (sY127, sY134) was the most common loci, involved in $16(66.7 \%)$ of the 24 microdeletions. The AZFa locus (represented in sY86) was involved in $5(20.8 \%)$, and the AZFc locus (represented in sY254) was involved in $3(12.5 \%)$ (Fig. 3, Table 2).

With regard to severity of disease, $9(56 \%)$ of the 16 microdeletions in azoospermic men and 7 (56\%) of 8 microdeletions in oligospermic men were in the AZFb locus. AZFc microdeletions were found in $12.5 \%$ of men with azoospermia and $12.5 \%$ of men with oligospermia. All of the AZFa deletions were found in patients with azoospermia (Table 2).

Among the 49 men with infertility, 32 (65\%) had idiopathic infertility and 17 (35\%) had varicocele. Twenty-

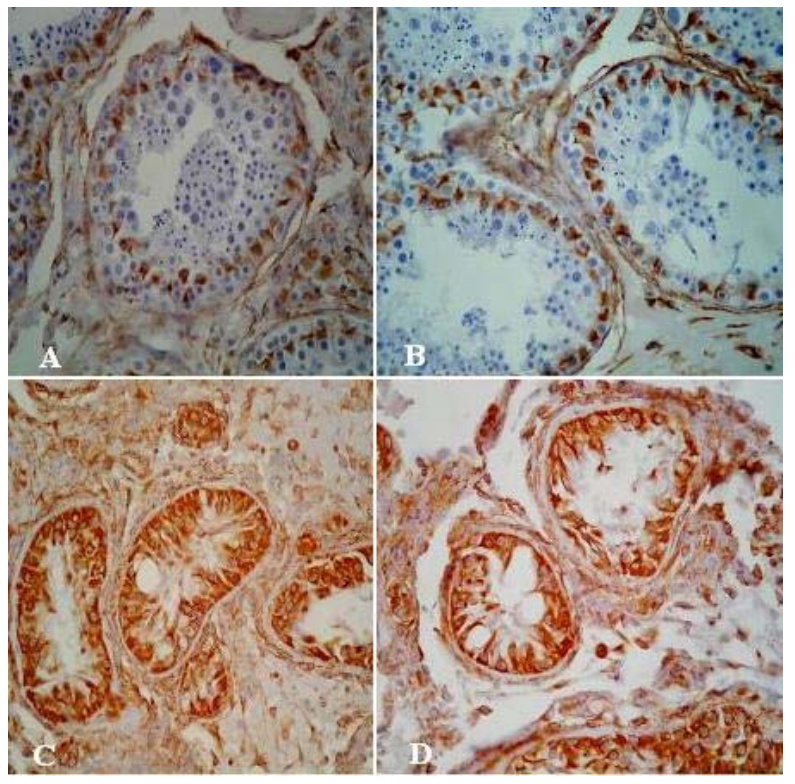

Fig. (2). Immunohistochemical staining for vimentin intermediate filaments within the seminiferous epithelium. The cytoplasm of Sertoli cells was uniformly immunopositive for vimentin in tubules with normal spermatogenesis (A) as well as in tubules with maturation arrest (B) and Sertoli cell-only syndrome (C and $\mathbf{D})$. Patients with idiopathic Sertoli cell-only syndrome had a mosaic pattern of differentiated and undifferentiated Sertoli cells. Nevertheless, such patients had a much smaller tubule diameter compared with patients with complete spermatogenesis. Original magnification $\times 200$. Scale bar $=150 \mu \mathrm{m}$. 


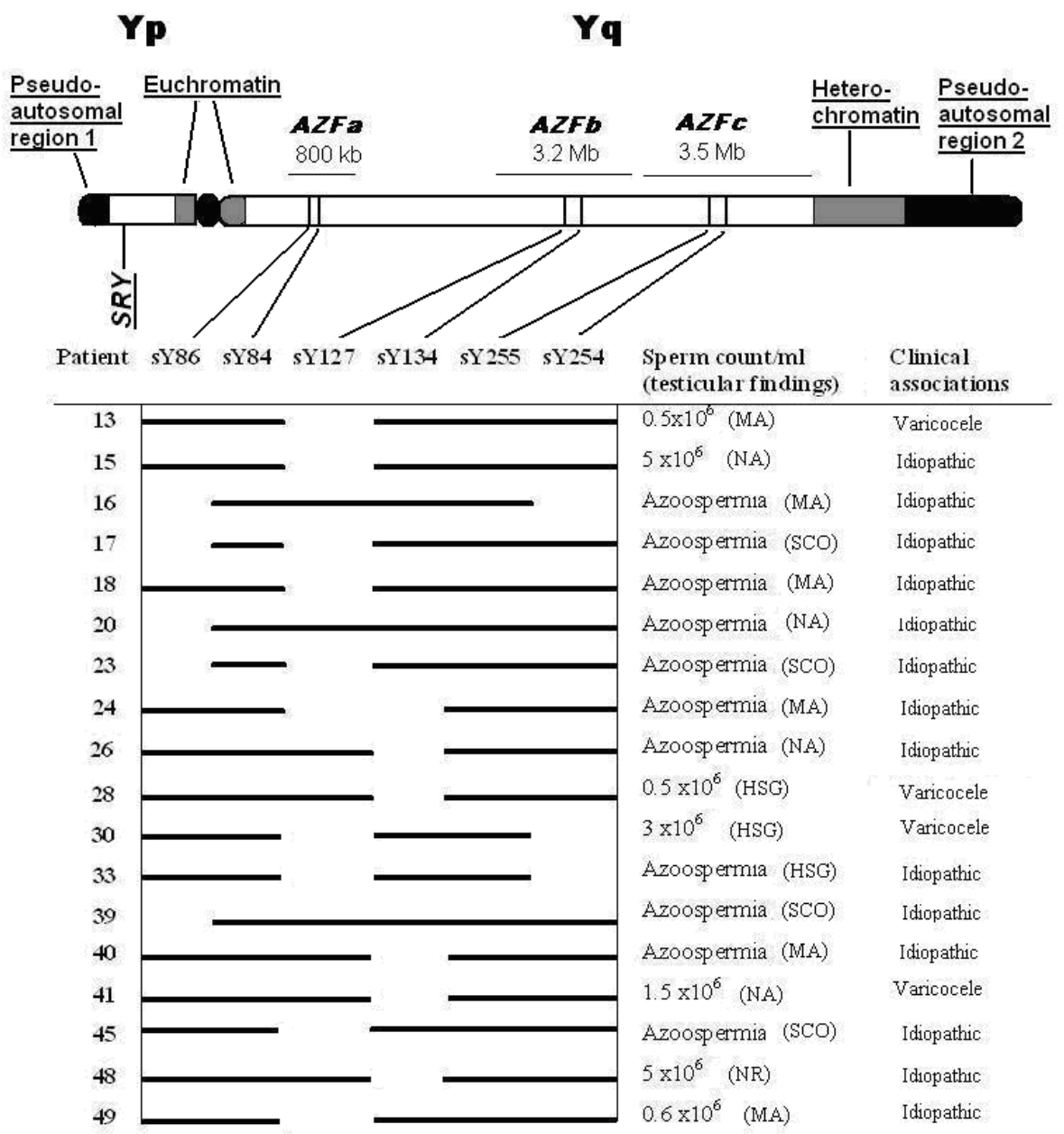

Fig. (3). Y chromosome ideogram represented spermatogenesis in Egyptian men with AZF loci deletions. The solid line represents the presence of the STS locus, while the blank is the deletion of the STS locus. MA= maturation arrest, SCO= Sertoli cell-only syndrome, NA= not available, $\mathrm{HSG}=$ hypospermatogenesis, $\mathrm{NR}=$ normal testicular findings.

Table 2. Frequency of Microdeletions According to STS and Sperm Status

\begin{tabular}{|c|c|c|c|c|c|c|c|}
\hline \multirow[t]{2}{*}{ Phenotype } & \multirow[t]{2}{*}{ Number of Deletions } & \multicolumn{2}{|c|}{$A Z F a$} & \multicolumn{2}{|c|}{$A Z F b$} & \multicolumn{2}{|c|}{$A Z F c$} \\
\hline & & $s Y 84$ & $s Y 86$ & $s Y 127$ & sY134 & $s Y 254$ & $s Y 255$ \\
\hline Azoo-spermia & $16(66.7 \%)$ & 0 & $\begin{array}{l}5 \\
(31.3 \%)\end{array}$ & $\begin{array}{l}6 \\
(37.5 \%)\end{array}$ & $\begin{array}{l}3 \\
(18.8 \%)\end{array}$ & $\begin{array}{l}2 \\
(12.5 \%)\end{array}$ & 0 \\
\hline Oligo-spermia & $8(33.3 \%)$ & 0 & 0 & $\begin{array}{l}4 \\
(50 \%)\end{array}$ & $\begin{array}{l}3 \\
(37.5 \%)\end{array}$ & $\begin{array}{l}1 \\
(12.5 \%)\end{array}$ & 0 \\
\hline Subtotal & $24(100 \%)$ & 0 & $\begin{array}{l}5 \\
(20.8 \%)\end{array}$ & $\begin{array}{l}10 \\
(41.7 \%)\end{array}$ & $\begin{array}{l}6 \\
(25 \%)\end{array}$ & $\begin{array}{l}3 \\
(12.5 \%)\end{array}$ & 0 \\
\hline \multicolumn{2}{|r|}{ Total } & \multicolumn{2}{|c|}{$20.8 \%$} & \multicolumn{2}{|c|}{$66.7 \%$} & \multicolumn{2}{|c|}{$12.5 \%$} \\
\hline
\end{tabular}

eight men (57\%) had non-obstructive azoospermia, and 21 $(43 \%)$ had severe oligospermia. Fourteen $(78 \%)$ of the 18 men with microdeletions had idiopathic infertility. The position and extent of the deletions are schematically diagrammed in Fig. 3.

Five $(28 \%)$ of the 18 infertile men with microdeletions had two separate deletions (cases \#16, 17, 23, 30, 33) (Fig. 3) localized on the Y chromosome, as validated by conventional Southern blotting (unpublished data). Azoospermia of maturation arrest was found in one of these five cases, SCO syndrome in two of the cases, and hypospermatogenesis in one case. The remaining case with two deletions was an infertile man with severe oligospermia (varicocele). 


\section{Haplotypes}

A wide range of combinations of microdeleted STSs were analyzed separately in infertile men. Each combination of deletions was considered a marker haplotype. Table $\mathbf{3}$ shows the most common 10 haplotypes (H1-H10) observed in infertile men. In the present study, we observed 7 of these 10 haplotypes in our patients. However, haplotypes H2, H5, and H6 (corresponding to single deletions in sY84, sY255, and sY254, respectively) were not detected in any of our patients. Although deletions in sY84 (H2) and sY254 (H6) did not occur per se, they did occur in combination with other deletions as part of haplotypes $\mathrm{H} 8$ and $\mathrm{H} 9$. $\mathrm{H} 3$ and $\mathrm{H} 4$ (corresponding to single deletions in sY127 and sY134, respectively) were the most common haplotypes. Of the four haplotypes consisting of multiple deletions, H7 (corresponding to sY86 and sY127) and H8 (corresponding to sY127 and sY254) were the most common (Table 3 ).

\section{Testicular Phenotypes}

Of the 18 men with microdeletions, 9 of 11 with deletions were azoospermic and five of seven with deletions were oligospermic. Of the nine patients with azoospermia, four had SCO syndrome, four had maturation arrest, and one presented with hypospermatogenesis. Of the five oligospermic patients, two displayed maturation arrest, two had hypospermatogenesis, and one had normal spermatogenesis. Most patients with a deletion that included the AZFa region had SCO syndrome. One patient with microdeletions in both the AZFa and AZFc loci had maturation arrest. The patients with deletions in the $\mathrm{AZFb}$ region showed a range of histological findings (Table 4). Immunohistochemical analyses showed that the cytoplasm of Sertoli cells was uniformly immunopositive for vimentin in all the biopsies, independent of spermatogenic impairment or the state of Sertoli cell differentiation. Patients with idiopathic SCO syndrome had a mosaic pattern of differentiated and undifferentiated Sertoli cells (Fig. 2). Nevertheless, these patients had a much smaller tubule diameter than patients with complete spermatogenesis.

\section{Hormone Levels}

For all patients, the levels of $\mathrm{LH}$ and testosterone were in the normal range (.2-12 IU/L and 7.4-52.4 IU/L, respectively). Although the mean FSH levels were elevated in the study population $(15.9 \pm 7.4 \mathrm{mIU} / \mathrm{ml})$, no significant differences in FSH levels were found between the patients with deletions and those without them.

\section{DISCUSSION}

Screening of $Y q$ is one of the most frequently performed molecular genetic tests in Egypt [14]. However, the impressive demand for $Y q$ screening deserves validation. In this regard, some important issues can be answered only by careful clinical assessment of a group of men with wellcharacterized microdeletions.

The reported frequencies of deletions in the AZF region of $Y q$ vary from $1 \%$ to $55 \%$, depending on a study's inclusion criteria and possibly on the STS markers used for screening [15]. Using six common STSs to screen the AZF region of $Y q$, we found a microdeletion frequency of $37 \%$ among 49 infertile Egyptian men. Microdeletion frequencies of $39 \%$ for azoospermic men and 33\% for severely oligospermic men were also observed. The prevalence in azoospermic men in the present study was similar to that reported by Foresta et al. [16]. The prevalence in oligospermic men was higher than what most studies have reported [17], but it was similar to that reported in a Tunisian population [18].

In monogenic disorders, some double deletions are present and may help to restore the reading frame of the mRNA transcript and consequently promote milder phenotypes $[19,20]$. The five cases of double deletions

Table 3. Composition of Haplotypes in the Study Population

\begin{tabular}{|c|c|c|c|c|}
\hline Locus (Haplotype) & STSs in the Haplotype & Azoo Group & Oligo Group & Total no. of Patients with Deletions (\%) \\
\hline $\mathrm{AZFa}(\mathrm{H} 1)$ & sY86 & 2 & 0 & $2(11 \%)$ \\
\hline $\mathrm{AZFa}(\mathrm{H} 2)$ & sY84 & 0 & 0 & 0 \\
\hline $\mathrm{AZFb}(\mathrm{H} 4)$ & sY134 & 2 & 3 & $5(28 \%)$ \\
\hline AZFc (H5) & sY255 & 0 & 0 & 0 \\
\hline $\mathrm{AZFc}(\mathrm{H} 6)$ & sY254 & 0 & 0 & 0 \\
\hline $\mathrm{AZFa}, \mathrm{b}(\mathrm{H} 7)$ & sY86+sY127 & 2 & 0 & $2(11 \%)$ \\
\hline $\mathrm{AZFb}(\mathrm{H} 10)$ & sY127+sY134 & 1 & 0 & $1(5.5 \%)$ \\
\hline \multicolumn{2}{|r|}{ Total } & $11(61 \%)$ & $7(39 \%)$ & $18(100 \%)$ \\
\hline
\end{tabular}


Table 4. Testicular Histopathology of the 18 Men with Microdeletions, According to Sperm Status

\begin{tabular}{|c|c|c|c|c|c|c|}
\hline Locus (STS) & No. of Deletions & SCO & HSG & MA & NA & Oligospermia \\
\hline \multicolumn{7}{|l|}{ AZFa } \\
\hline (sY86) & 5 & 3 & 0 & 1 & 1 & 0 \\
\hline \multicolumn{7}{|l|}{$\mathbf{A Z F b}$} \\
\hline (sY127) & 10 & 3 & 1 & 2 & 0 & 1 (HSG), 2 (MA), 1 (NA) \\
\hline (sY134) & 6 & 0 & 0 & 2 & 1 & 1 (HSG), 1 (NR), 1 (NA) \\
\hline \multicolumn{7}{|l|}{ AZFc } \\
\hline (sY254) & 3 & 0 & 1 & 1 & 0 & 1 (HSG) \\
\hline
\end{tabular}

$\mathrm{SCO}=$ Sertoli cell-only syndrome, $\mathrm{HSG}=$ hypospermatogenesis, $\mathrm{MA}=$ maturation arrest, $\mathrm{NA}=$ not available, $\mathrm{NR}=$ normal testicular findings.

identified within the AZF region of the $\mathrm{Y}$ chromosome in this study clearly increased the severity of the clinical phenotypes, as four of the five cases showed azoospermia on clinical investigation. These separate deletions might be due to the creation of alternative initiation and termination codons in the coding sequence of the mRNA transcript. Further investigation could help someone to develop procedures for reducing the severity of clinical phenotypes, by disrupting the translational fidelity and consequently restore the correct frame $[8,19,20]$.

Most studies have found the highest frequency of microdeletions in the $\mathrm{AZFc}$ locus, followed by the $\mathrm{AZFb}$ locus [21, 22] and, less commonly, the AZFa locus [23, 24]. In the present study the highest frequency of microdeletions was found in the AZFb locus, followed by the AZFa (20.8\%) and AZFc (12.5\%) loci. Our findings are similar to those [25] that, in contrast to most reports, found that $54 \%$ of patients with $Y q$ microdeletions had a deletion involving the $\mathrm{AZFb}$ region. Our results, combined with those of Brandell et al. [25] suggest that the AZFb locus is a good candidate for future functional studies.

Generally, ethnic differences might be associated with variations in both the frequency and pattern [26] of Ychromosome microdeletions. For instance, an unusually low frequency of microdeletions $(3.3 \%)$ has been reported in infertile Turkish men [27]. In terms of patterns, the STSs sY240 and sY129 are commonly deleted in infertile Japanese men [28], while sY269 [29] and USP9Y [30] are more commonly deleted in Italian men and sY100 in French men [31].

Although STSs sY84 (AZFa) and sY255 (AZFc) are frequently recommended for traditional analyses, we did not detect deletions in either of these loci in our population. More deletions would be found if more primer sets for multiplex PCR were used [32]. However, this would contradict the recommendations of the European Academy of Andrology [33], which suggest that more than $90 \%$ of microdeletions can be detected using six STSs to screen the AZF region (i.e., two STSs for each AZF locus).
We also found that only azoospermic patients had microdeletions in the AZFa locus and that most of these patients were found to have SCO syndrome. Patients with isolated $\mathrm{AZFb}$ microdeletions had histological differences ranging from SCO syndrome to normal spermatogenesis. This result was consistent with published data showing that patients with $\mathrm{AZFb}$ deletions are as phenotypically heterogeneous as those with AZFc deletions [34]. The finding of normal spermatogenesis in the presence of $\mathrm{Y}$ chromosome microdeletions is an extremely rare finding, which has been previously reported by Pryor et al. [35] to be associated with spermatic duct obstruction. The possibility of areas of focal spermatogenesis in the presence of testicular pathologies [36] may explain this finding. Our findings support the view that the worst spermatogenic defects are caused by deletions of the AZFa region [37]. Identical microdeletions may be associated with diverse types of tubular damage, as recently reported [38], but the only method for distinguishing the specific tubular alterations in azoospermic or severely oligospermic men is to directly analyze their testicular structures by diagnostic open biopsy or fine-needle aspiration.

In our study, we detected microdeletions in 4 (23\%) of 17 of patients with varicocele. Moro et al. [39] found a microdeletion frequency of $17.5 \%$ among patients with varicocele and severe oligospermia, although no genetic abnormalities in patients with varicocele and only mild oligospermia were noted. It has been found that $8 \%$ of infertile men with varicocele have microdeletions of STSs in the AZF region [40]. In contrast, Kleiman et al. [24] did not detect any $Y q$ deletions in men with varicocele, regardless of their sperm counts. Although varicoceles are associated with infertility, only $1(\sim 17 \%)$ of 6 men with a varicocele presents with infertility [41]. Microdeletions may have been the primary cause of infertility in our four patients with varicoceles, although the varicocele itself can worsen the testicular alteration.

Our immunohistochemical analyses showed that the cytoplasm of Sertoli cells was uniformly immunopositive for vimentin in all of the biopsies performed, independent of 
spermatogenic impairment. Kleiman et al. [5] studied the involvement of Sertoli cells in different spermatogenesis impairment by an immunohistomorphometric technique using cytokeratin-18 (CK-18) and vimentin [42], which are co-expressed in the cytoplasm of Sertoli cells during prenatal and pubertal differentiation [43]. They came to the conclusion, after examining testicular biopsies from nine men with microdeletions, that AZF deletions have no impact on the Sertolicell maturation process. They also concluded that there is no association between spermatogenesis and the maturation state of the Sertoli cells.

Finally, no significant differences in the mean levels of testosterone, LH, or FSH were found between patients with deletions and those without them. Similarly, other recent studies comparing FSH levels between patients with and without deletions found no significant differences [37]. Together, these results suggest that hormone levels are not a likely indicator of who may be at risk of a deletion.

Intracytoplasmic sperm injection (ICSI) now provides fertility in many cases of severe idiopathic spermatogenic failure and obstructive azoospermia. Genetic causes must be sought by systematically evaluating infertile men and affected couples who are informed about the implications of diagnoses for assisted reproduction and their potential offspring [44].

Partial deletions of the AZFc region might prospectively influence the fertility status of the patients. It remains unclear which of the genes located in the deleted regions are important for the progression of spermatogenesis. X-linked genes can also affect male infertility. For example, mutations in X-linked genes crucial for spermatogenesis will have an immediate impact on sperm production. The $\mathrm{X}$-linked genes NXF2, USP26, and TAF7L were previously reviewed for the presence of mutations [45]. Recently, Stouffs et al. [45] have studied five autosomal genes: SYCP3, MSH4, DNMT3L, STRA8, and ETV5. They detected changes in the latter two genes that were absent in a control population of men with normozoospermia. Functional analysis of the changes in ETV5 and the localization of the change observed in STRA8 showed that these alterations were probably not the cause of the fertility problems in these men. These reports could be concluded that mutations in X-linked genes in humans, presumed to be important for spermatogenesis, have been disappointing.

Based on the results of our study, we recommend that all patients with a sperm concentration lower than $5 \times 10^{6} / \mathrm{ml}-$ especially those with severe testiculopathy-must be screened for Y-chromosome microdeletions, regardless of other concomitant causes of testicular damage. The detection of a deletion allows the clinician to avoid unnecessary and expensive treatments for determining the cause of infertility in a patient.

\section{CONCLUSION}

We conclude that the tag STSs from our study can be used to screen infertile Egyptian men for $Y q$ microdeletions before assisted reproduction is initiated as a treatment. To efficiently detect these deletions in the Egyptian population, we recommend performing multiplex PCR with a combination of three STSs—sY86, sY127, and sY134-as a first step.

\section{ACKNOWLEDGEMENTS}

We thank Kerry Aradhya for help with English. The authors are grateful to the staff of the Department of Andrology, Faculty of Medicine-Cairo, for their fruitful services to fulfill patients' records.

\section{LIST OF ABBREVIATIONS}

$\begin{aligned} \text { AZF } & =\text { Azoospermia factor CK-18: cytokeratin-18 } \\ \text { FSH } & =\text { Follicle stimulating hormone } \\ \text { GTG } & =\text { G-banding by Trypsine-Giemsa } \\ \text { HSG } & =\text { Hypospermatogenesis } \\ \text { ICSI } & =\text { Intracytoplasmic sperm injection } \\ \text { IVF } & =\text { In vitro fertilization } \\ \text { LH } & =\text { Leutinizing hormone } \\ \text { MA } & =\text { Maturation arrest } \\ \text { PCR } & =\text { Polymerase chain reaction } \\ \text { SCO } & =\text { Sertoli-cell-only } \\ \text { STS } & =\text { Sequence-tagged site }\end{aligned}$

\section{REFERENCES}

[1] McElreavey K, Chantot-Bastaraud S, Ravel C, Mandelbaum J, Siffroi JP. Y chromosome and male infertility: what is a normal Y chromosome? J Soc Biol 2008; 202: 135-41.

[2] Vogt PH. AZF deletions and Y chromosomal haplogroups: history and update based on sequence. Hum Reprod Update 2005; 11: 31936.

[3] Egyptian Fertility Care Society. Community-based study of the prevalence of infertility and its etiological factors in Egypt: (1) The population-based study. Cairo Egyptian Ferti Care Soc 2009.

[4] Boivin J, Bunting L, Collins JA, Nygren KG. International estimates of infertility prevalence and treatment-seeking: potential need and demand for infertility medical care. Hum Reprod 2007; 22(6): 1506-12.

[5] Kleiman SE, Bar-Shira Maymon B, Yogev L, Paz G, Yavetz H. The prognostic role of the extent of $\mathrm{Y}$ microdeletion on spermatogenesis and maturity of Sertoli cells. Hum Reprod 2001; 16: 399-402.

[6] Hellani A, Al-Hassan S, Al-Duraihim A, Coskun S. Y chromosome microdeletions: are they implicated in teratozoospermia? Hum Reprod 2005; 20: 3505-9.

[7] Simoni M, Bakker E, Krausz C. EAA/EMQN best practice guidelines for molecular diagnosis of $\mathrm{y}$-chromosomal microdeletions. State of the art 2004. Int J Androl 2004; 27: 240-9.

[8] Elhawary NA, Shawky RM, Hashem N. Frameshift deletion mechanisms in Egyptian Duchenne and Becker muscular dystrophy families. Mol Cells 2004; 18: 141-9.

[9] Hsu CC, Kuo PL, Chuang L, et al. Uniform deletion junctions of complete azoospermia factor region c deletion in infertile men in Taiwan. Asian J Androl 2006; 8: 205-11.

[10] Vogt PH, Edelmann A, Kirsch S, et al. Human Y chromosome azoospermia factors (AZF) mapped to different subregions in Yq11. Hum Mol Genet 1996; 5: 933-43.

[11] Sambrook J, Fritsh EF, Maniatis T. Molecular cloning: a laboratory manual. New York: Cold Spring Harbor Press 1989.

[12] Barrett JC, Fry B, Maller J, Daly MJ. Haploview: analysis and visualization of LD and haplotype maps. Bioinformatics 2005; 21 : 263-5.

[13] World Health Organization (WHO). Laboratory manual for examination of human semen and cervical mucus interaction. $3^{\text {rd }}$ ed. Cambridge: Cambridge University Press 1999.

[14] El Awady MK, El Shater SF, Ragaa E, et al. Molecular study on Y chromosome microdeletions in Egyptian males with idiopathic infertility. Asian J Androl 2004; 6: 53-7.

[15] Benedicenti F, Castellan C. Interesting suggestions about Yq deletions. Fertil Steril 2009; 91(1): 300-1. 
[16] Foresta C, Ferlin A, Garolla A, et al. Y-chromosome deletions in idiopathic severe testiculopathies. J Clin Endocrinol Metab 1997; 82: $1075-80$

[17] Ceylan GG, Ceylan C, Elyas H. Genetic anomalies in patients with severe oligozoospermia and azoospermia in eastern Turkey: a prospective study. Genet Mol Res 2009; 8(3): 915-22.

[18] Hadjkacem-Loukil L, Ayadi I, Bahloul A, Ayadi H, AmmarKeskes L. Tag STS in the AZF region associated with azoospermia in a Tunisian population". J Androl 2007; 28(5): 652-8.

[19] Hoffman EP. Skipping toward personalized molecular medicine. N Engl J Med 2007; 357: 2719-22.

[20] Hoop RC, Russo LS, Riconda DL, Schwartz LS, Hoffman EP. Restoration of half the normal dystrophin sequence in a doubledeletion Duchenne muscular dystrophy family. Am J Med Genet 1994; 49: 323-7.

[21] Le Bourhis C, Siffroi JP, McElreavey K, Dadoune JP. Y chromosome microdeletions and germinal mosaicism in infertile males. Mol Hum Reprod 2000; 6: 688-93.

[22] Martinez MC, Bernabe MJ, Gomez E, et al. Screening for AZF deletion in a large series of severely impaired spermatogenesis patients. J Androl 2000; 21: 651-5.

[23] Reijo R, Lee TY, Salo P, et al. Diverse spermatogenic defects in humans caused by $\mathrm{Y}$ chromosome deletions encompassing a novel RNA-binding protein gene. Nat Genet 1995; 10: 383-93.

[24] Kleiman SE, Yogev L, Gamzu R, et al. Three-generation evaluation of Y-chromosome microdeletion. J Androl 1999; 20: 394-8.

[25] Brandell RA, Mielnik A, Liotta D, et al. AZFb deletions predict the absence of spermatozoa with testicular sperm extraction: preliminary report of a prognostic genetic test. Hum Reprod 1998; 13: 2812-5.

[26] Balkan M, Tekes S, Gedik A. Cytogenetic and Y chromosome microdeletion screening studies in infertile males with Oligozoospermia and Azoospermia in Southeast Turkey. J Assist Reprod Genet 2008; 25: 559-65.

[27] Sargin CF, Berker-Karauzum S, Manguoglu E, et al. AZF microdeletions on the $\mathrm{Y}$ chromosome of infertile men from Turkey. Ann Genet 2004; 47: 61-8.

[28] Kato H, Komori S, Nakata Y, et al. Screening for deletions in interval D16-22 of the $\mathrm{Y}$ chromosome in azoospermic and oligozoospermic Japanese men. J Hum Genet 2001; 46: 110-4.

[29] Ferlin A, Arredi B, Foresta C. Genetic causes of male infertility. Reprod Toxicol 2006; 22: 133-41.
[30] Luddi A, Margollicci M, Gambera L, et al. Spermatogenesis in a man with complete deletion of USP9Y. N Engl J Med 2009; 360: 881-5.

[31] Ravel C, Chantot-Bastaraud S, El Houate B, et al. Y-chromosome AZFc structural architecture and relationship to male fertility. Fertil Steril 2009; 92(6): 1924-33.

[32] Dada R, Gupta NP, Kucheria K. Molecular screening for $\mathrm{Yq}$ microdeletion in men with idiopathic oligozoospermia and azoospermia. J Biosci 2003; 28(2): 163-8.

[33] Simoni M, Bakker E, Eurlings MC, et al. Laboratory guidelines for molecular diagnosis of Y-chromosomal microdeletions. Int Androl 1999; 22: 292-9.

[34] Poongothai J, Gopenath TS, Manonayaki S. Genetics of human male infertility. Singapore Med J 2009; 50: 336-47.

[35] Pryor JL, Kent-First M, Muallem A, et al. Microdeletions in the Y Chromosome of Infertile Men. N Engl J Med 1997; 336: 534-40.

[36] Altay B, Hekimgil M, Cikili N, Turna B, Soydan S Histopathological mapping of open testicular biopsies in patients with unobstructive azoospermia. BJU Int 2001; 87: 834-7.

[37] Fernando L, Gromoll J, Weerasooriya TR, Nieschlag E, Simoni M. Y-chromosomal microdeletions and partial deletions of the Azoospermia Factor c (AZFc) region in normozoospermic, severe oligozoospermic and azoospermic men in Sri Lanka. Asian J Androl 2006; 8: 39-44.

[38] Mitra A, Dada R, Kumar R, et al. Screening for Y-chromosome microdeletions in infertile Indian males: utility of simplified multiplex PCR. Indian J Med Res 2008; 127: 124-32.

[39] Moro E, Marin P, Rossi A, Garolla A, Ferlin A. Y chromosome microdeletions in infertile men with varicocele. Mol Cell Endocrinol 2000; 161: 67-71.

[40] Van Landuyt L, Lissens W, Stouffs K, et al. Validation of a simple Yq deletion screening programme in an ICSI candidate population. Mol Hum Reprod 2000; 6: 291-7.

[41] Sylora JA, Pryor JL. Varicocele. Curr Ther Endocrinol Metab 1994; 5: 309-14

[42] Maymon BB, Paz G, Yogev L, et al. Immunohistochemical identification of testicular germ cells--preliminary report. Harefuah 2000; 139: 179-82, 247.

[43] Aumuller G, Schulze C, Viebahn C. Intermediate filaments in Sertoli cells. Microsc Res Technol 1992; 20: 50-72.

[44] McLachlan RI, O'Bryan MK. State of the art for genetic testing of infertile men. J Clin Endocrinol Metab 2010; 95(3): 1013-24.

[45] Stouffs K, Vandermaelen D, Tournaye H, Liebaers I, Van Steirteghem A, Lissens W. Genetics and male infertility. Hum Reprod Update 2009; 15(6): 623-37.

This is an open access article licensed under the terms of the Creative Commons Attribution Non-Commercial License (http: //creativecommons.org/licenses/bync/3.0/) which permits unrestricted, non-commercial use, distribution and reproduction in any medium, provided the work is properly cited. 